\title{
Rhenium-osmium (Re-Os) geochronology of crude oil from lacustrine source rocks of the Hailar Basin, NE China
}

\author{
Qi-An Meng ${ }^{1,2} \cdot$ Xue Wang $^{1,2} \cdot$ Qiu-Li Huo ${ }^{1,2} \cdot$ Zhong-Liang Dong $^{1,2} \cdot$ Zhen Li $^{3} \cdot$ Svetlana G. Tessalina ${ }^{3}$. \\ Bryant D. Ware ${ }^{3} \cdot$ Brent I. A. Mclnnes ${ }^{3} \cdot$ Xiao-Lin Wang $^{4} \cdot$ Ting Liu $^{1,2} \cdot$ Li Zhang $^{1,2}$
}

Received: 3 July 2020 / Published online: 3 November 2020

(c) The Author(s) 2020

\begin{abstract}
Re-Os radiometric dating of crude oil can be used to constrain the timing of hydrocarbon generation, migration or charge. This approach has been successfully applied to marine petroleum systems; however, this study reports on its application to lacustrine-sourced natural crude oils. Oil samples from multiple wells producing from the Cretaceous Nantun Formation in the Wuerxun-Beier depression of the Hailar Basin in NE China were analysed. Subsets of the Re-Os data are compatible with a Cretaceous hydrocarbon generation event (131.1 $\pm 8.4 \mathrm{Ma}$ ) occurring within $10 \mathrm{Myr}$ of deposition of the Nantun Formation source rocks. In addition, two younger age trends of $54 \pm 12 \mathrm{Ma}$ and $1.28 \pm 0.69 \mathrm{Ma}$ can be regressed from the Re-Os data, which may reflect the timing of subsequent hydrocarbon generation events. The Re-Os geochronometer, when combined with complementary age dating techniques, can provide direct temporal constraints on the evolution of petroleum system in a terrestrial basin.
\end{abstract}

Keywords Re-Os dating $\cdot$ Lacustrine crude oils $\cdot$ Hailar basin $\cdot$ Petroleum system evolution

\section{Introduction}

Oil and natural gas are expected to meet over $50 \%$ of the world's energy needs by 2040 (ExxonMobil 2019). Providing temporal constraints on the evolution of a petroleum system within a sedimentary basin is of fundamental importance to exploration targeting by industry. The rhenium-osmium (Re-Os) geochronometer is a promising absolute dating technique for organic-rich rocks and their

Edited by Jie Hao

Zhen Li

zhen.li@curtin.edu.au

1 Exploration and Development Research Institute, Daqing Oilfield Co., Ltd., Daqing 163712, Heilongjiang, China

2 Heilongjiang Provincial Key Laboratory for the Study of Tight Oil and Shale Oil Accumulation, Daqing 163712, Heilongjiang, China

3 John de Laeter Centre, Faculty of Science and Engineering, Curtin University, GPO Box U1987, Perth, WA 6485, Australia

4 State Key Laboratory for Mineral Deposits Research, School of Earth Sciences and Engineering, Nanjing University, Nanjing 210023, Jiangsu, China associated hydrocarbon derivatives (see reviews in Cohen 2004; Stein and Hannah 2015; Li et al. 2017; Liu and Selby 2018). Both Re and Os are redox-sensitive and organophilic, and can be enriched in hydrocarbon source rocks, tar sands, crude oil, and bitumen. Based on the naturally occurring radiometric decay of ${ }^{187} \mathrm{Re}$ to ${ }^{187} \mathrm{Os}$, Re-Os geochronology of such organic-rich samples has the potential to constrain the timing of hydrocarbon maturation, migration or charge in petroleum systems (Selby and Creaser 2005a). Moreover, the initial ${ }^{187} \mathrm{Os} /{ }^{188} \mathrm{Os}$ composition of liquid hydrocarbons can potentially fingerprint their source rock provenance (Finlay et al. 2011).

Previous studies have successfully applied Re-Os geochronology to petroleum systems in marine-dominated basin environments (Ravizza and Turekian 1989; Cohen et al. 1999; Selby and Creaser 2005a, b; Rooney et al. 2010; Finlay et al. 2011; Lillis and Selby 2013; Zhu et al. 2013; Bertoni et al. 2014; Ge et al. 2016, 2018; Georgiev et al. 2019). However, lacustrine sedimentary basins-which are important sources of hydrocarbons in China-can be more challenging ( $\mathrm{Li}$ et al. 2017) because sediments of subaerial provenance are likely to have low initial Re and Os concentrations (Creaser et al. 2008; Baioumy et al. 2011). Here, we report the first successful 
Re-Os radiometric dating of lacustrine-sourced natural crude oils from the Wuerxun-Beier depression of the Hailar Basin in NE China, providing direct Re-Os dating constraints on a petroleum system operating within a terrestrial basin. By combining these data with previous basin histories and apatite fission-track analysis, we not only investigate the temporal evolution of the WuerxunBeier petroleum system, but also demonstrate the potential application of the Re-Os chronometer in better understanding other terrestrial petroliferous basins worldwide.

\section{Geological setting}

Covering an area of more than $70,000 \mathrm{~km}^{2}$, the Hailar Basin is located in Hulun Buir of the Inner Mongolia Autonomous Region and is one of the most important petroliferous continental basins in NE China (Fig. 1). The Wuerxun-Beier depression, with an area of about $5,220 \mathrm{~km}^{2}$, is a large second-order tectonic unit in the central fault belt of the Hailar Basin (Zhang and Peng 2002; Wu et al. 2006; Cui and Ren 2011). The Wuerxun-Beier petroleum system has received considerable attention due to its huge resource potential with total proved reserves of oil and gas exceeding 200 million

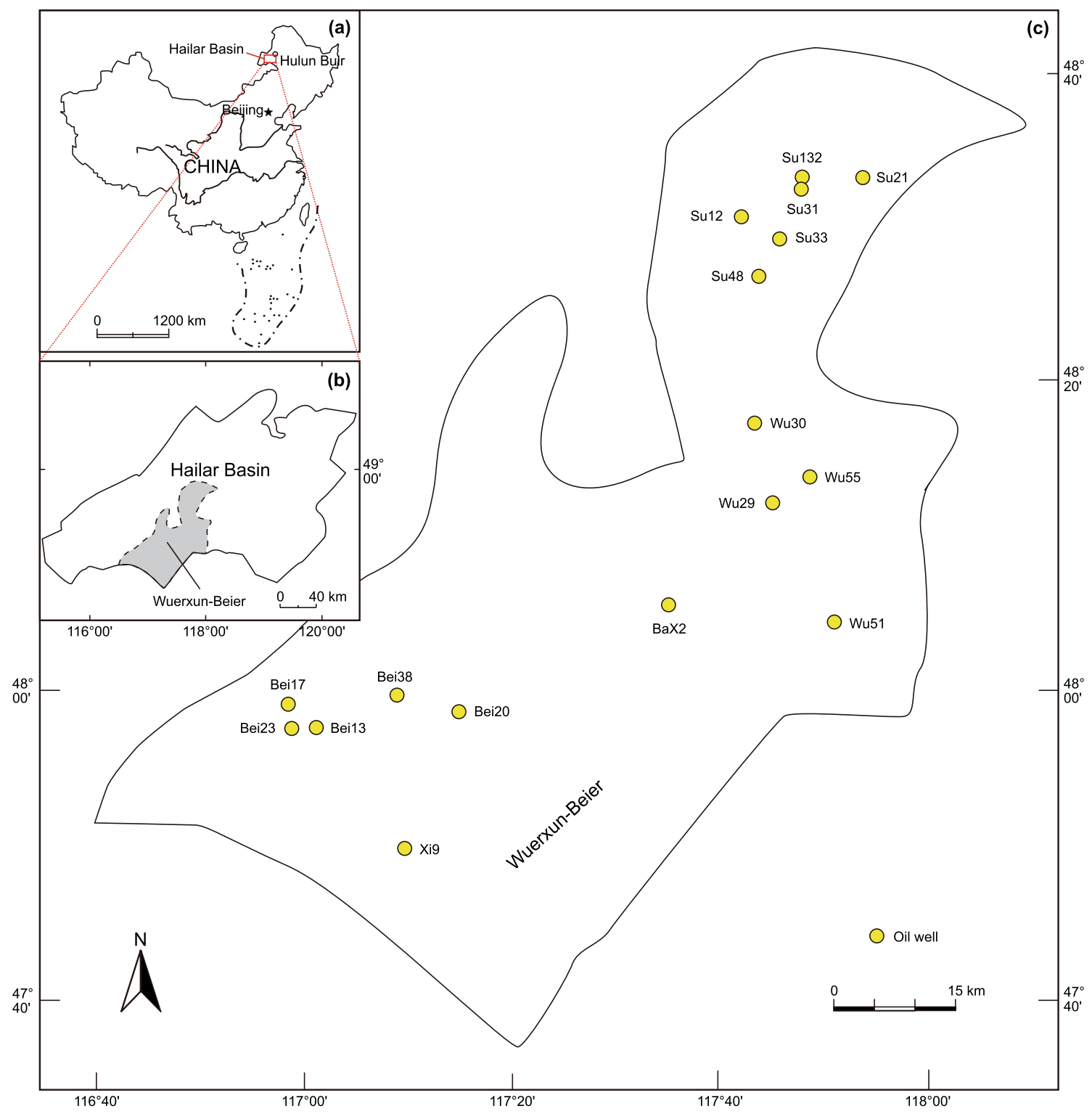

Fig. 1 a Schematic map shows the location of the Hailar Basin. b Location of the Wuerxun-Beier depression in the Hailar Basin (Modified after Gong 2012). c Locations of oil wells used for sampling in this study 
tons (Ping et al. 2013), making it a major target of hydrocarbon exploration in the basin.

Six main sedimentary sequences are recognised in the Wuerxun-Beier depression resting on the Paleozoic metamorphic basement (Fig. 2), from bottom to top the Lower Cretaceous Tamulangou, Tongbomiao, Nantun, Damoguaihe and Yimin Formations, as well as the Upper Cretaceous Qingyuangang Formation (Ping et al. 2013;

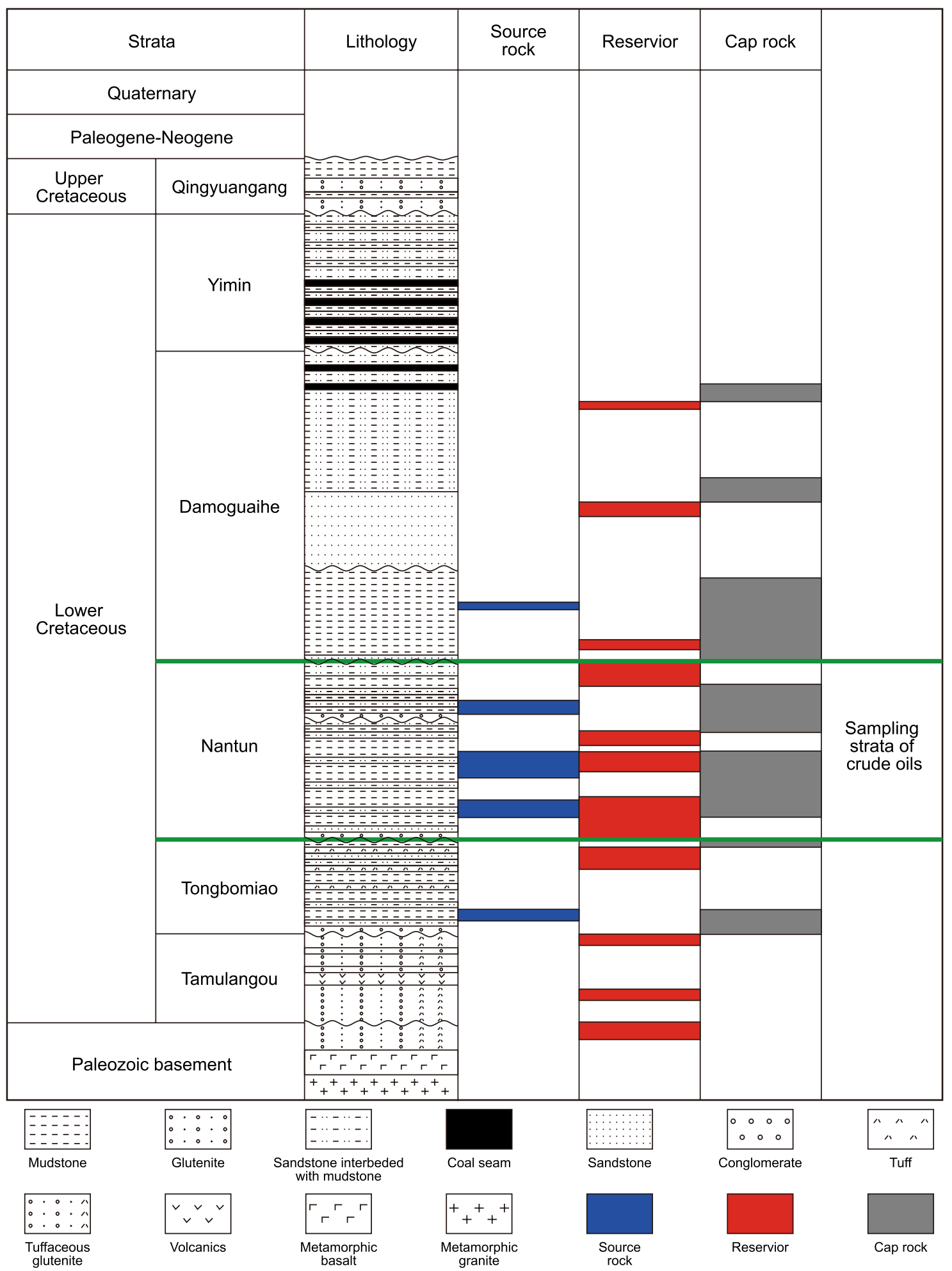

Fig. 2 Simplified stratigraphic column of the Wuerxun-Beier depression in the Hailar Basin 
Wang et al. 2018). Previous studies observed possible source rocks (including organic-rich dark mudstones, coal mudstones, and coal seams, etc.) in the Tongbomiao $\left(\mathrm{K}_{1} t\right)$ Formation, Nantun $\left(\mathrm{K}_{1} n\right)$ Formation, and Damoguaihe $\left(\mathrm{K}_{1} d\right)$ Formation (Fig. 2). The $\mathrm{K}_{1} t$ Formation source rocks mainly contain thermally mature to postmature Type II kerogen, and the $\mathrm{K}_{1} n$ Formation source rocks have both mature Type I and mature Type II kerogens. In contrast, the $\mathrm{K}_{1} d$ Formation source rocks contain immature Type III kerogen.

Recent investigations of oil-oil and oil-source rock correlations by chemometric methods suggest that the highest contributing source rocks for the Wuerxun-Beier petroleum system is the $\mathrm{K}_{1} n$ Formation, with the $\mathrm{K}_{1} t$ and $\mathrm{K}_{1} d$ Formations providing only a limited contribution (Wang et al. 2018). The $\mathrm{K}_{1} n$ Formation source rocks are lacustrine sediments ranging from deepwater mudstones to marshy deltaic sediments (Lu et al. 2012) with interbedded sandstones and mudstones (Fig. 2). Furthermore, because the petroliferous horizons in the Wuerxun-Beier depression occur mainly within the $\mathrm{K}_{1} n$ Formation, it has been argued that it functions as a stratigraphically self-contained (source, reservoir and seal unit) petroleum system in the Hailar Basin (Fig. 2) (Ping et al. 2013).

\section{Samples and methods}

Crude oil samples were recovered from 17 producing petroleum wells from the $\mathrm{K}_{1} n$ Formation in the Hailar Basin, providing a broad geographic distribution of Nantun oils from the Wuerxun-Beier petroleum system (Fig. 1). Because the asphaltene fraction (the heavy organic fraction) is the main carrier of $\operatorname{Re}(>90 \%)$ and Os $(>83 \%)$ within typical crude oil samples (Selby et al. 2007; Liu and Selby 2018), we separated asphaltene from the Wuerxun-Beier Nantun crudes to determine their ${ }^{187} \mathrm{Re} /{ }^{188} \mathrm{Os}$ and ${ }^{187} \mathrm{Os} /{ }^{188} \mathrm{Os}$ ratios.

The $\mathrm{Re}-\mathrm{Os}$ isotopic analyses were carried out at the John de Laeter Centre (JdLC) at Curtin University in Perth, Western Australia. The asphaltene contents were separated from the Wuerxun-Beier Nantun crudes using a modified protocol from Selby et al. (2007). For each sample, $1 \mathrm{~g}$ of crude oil was weighed into a $50 \mathrm{~mL}$ centrifuge tube. For separation of the asphaltene component, $40 \mathrm{~mL}$ of $n$-heptane was added to each centrifuge tube. To thoroughly mix the oil and $n$-heptane, the tubes were first shaken by hand for $60 \mathrm{~s}$ and then placed on a Vari-Mix ${ }^{\mathrm{TM}}$ Platform Rocker at $200 \mathrm{rpm}$ (revolutions per minute) for $24 \mathrm{~h}$ (Fig. 3a). The following day the samples were transferred into a refrigerator set to $5-6{ }^{\circ} \mathrm{C}$ and allowed to sit overnight. The samples were then removed from the refrigerator and centrifuged at $2500 \mathrm{rpm}$ for $5 \mathrm{~min}$, after which, in most samples, the asphaltene can be observed at the base of the centrifuge tube. Once each sample has been centrifuged, the $n$-heptane (and thus the maltene fraction) were decanted into a waste beaker (Fig. 3b). After being weighed, double-distilled chloroform $\left(\mathrm{CCl}_{4}\right)$ was then pipetted into each $50 \mathrm{~mL}$ centrifuge tube to transfer the asphaltene separate into Carius tubes for digestion. If a sample did not contain enough asphaltene after separation (about 120 to $200 \mathrm{mg}$ of asphaltene was targeted for each $\mathrm{Re}-\mathrm{Os}$ analyses), the process was repeated on another $1 \mathrm{~g}$ of crude oil and the asphaltene aliquots were mixed and weighed before being transferred to Carius tubes.

The Carius tubes were laid flat onto a sloped hotplate at $70{ }^{\circ} \mathrm{C}$ to evaporate all $\mathrm{CCl}_{4}$ before digestion. After a $\mathrm{Re}$ and Os tracer was added to each sample, the samples were dissolved in inverse aqua-regia $\left(3: 1 \mathrm{HNO}_{3} / \mathrm{HCl}\right)$ at $240{ }^{\circ} \mathrm{C}$ within sealed Carius tubes (Fig. $4 \mathrm{a}$ ) for at least $48 \mathrm{~h}$ (Selby and Creaser 2001). The solvent extraction method

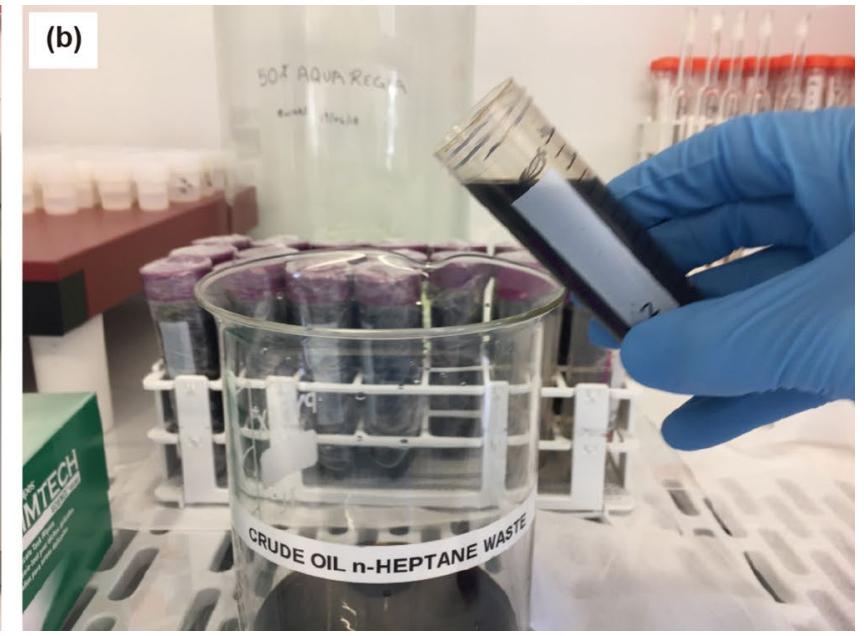

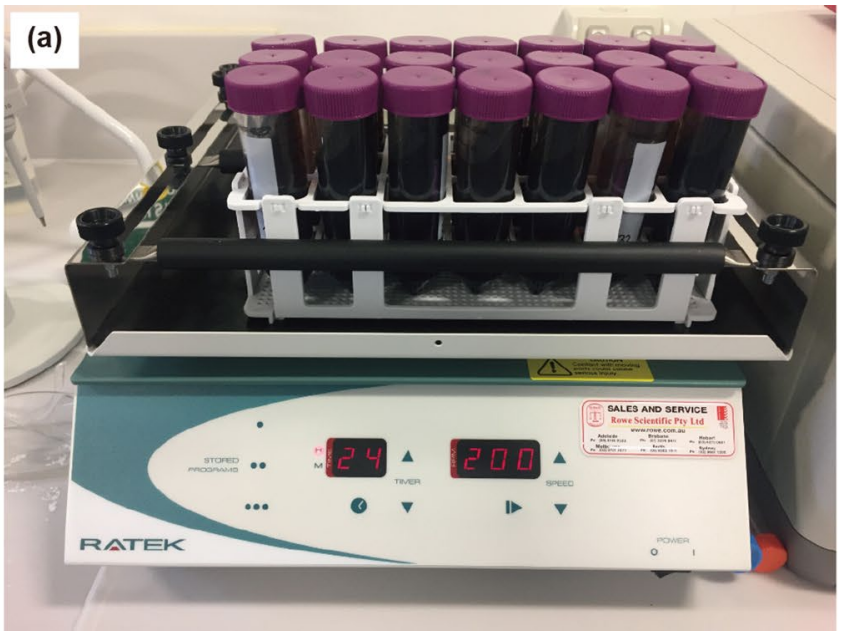

Fig. 3 Asphaltene separation for the Wuerxun-Beier Nantun oils in the Hailar Basin. a $1 \mathrm{~g}$ of oil sample in $40 \mathrm{~mL}$ of $n$-Heptane mixing overnight. b Decanting of $n$-Heptane and maltene leaving asphaltene separate in the bottom of the centrifuge tube 

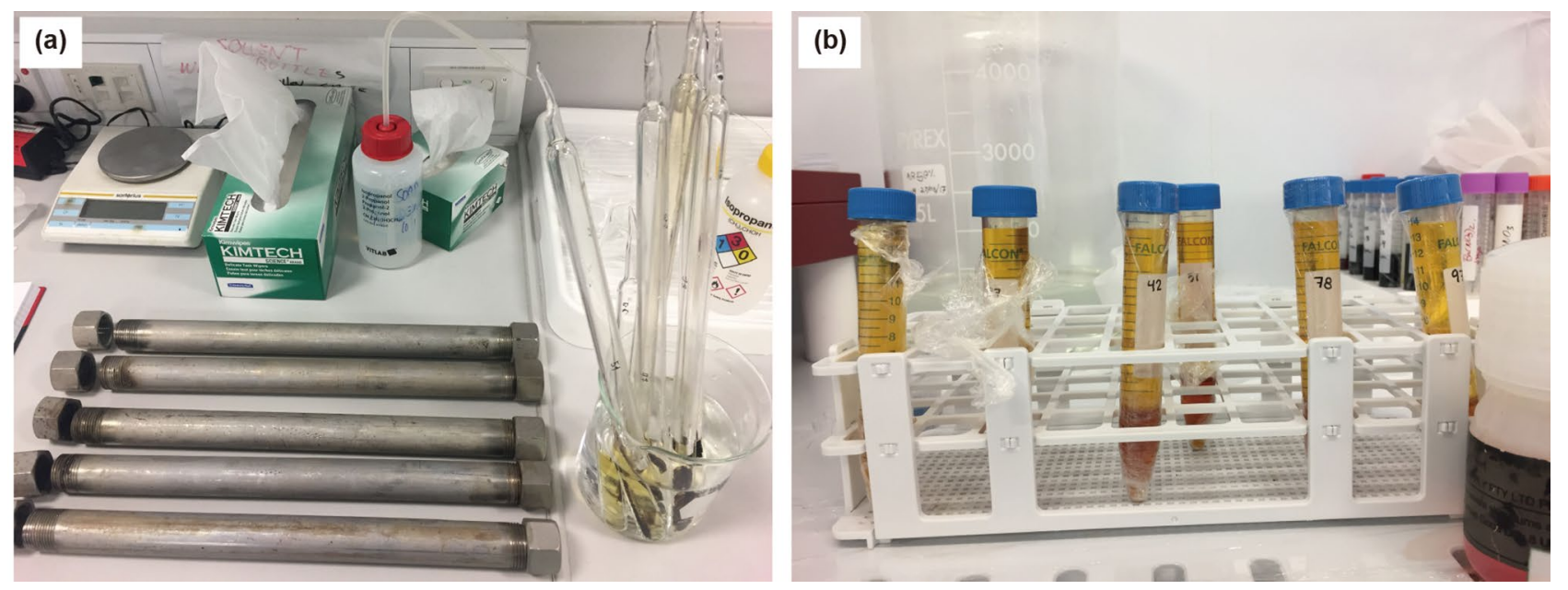

Fig. 4 Sample digestion and solvent extraction for the Wuerxun-Beier Nantun oils in the Hailar Basin. a Preparing sealed Carius tubes and protective metal jackets for digestion. b Oil samples in centrifuge tubes ready for centrifuge and Os solvent extraction. Reverse aqua regia (upper part) can be observed not mixing with the chloroform (lower part)

was utilised to extract the Os from the inverse aqua-regia (Fig. 4b) and a micro-distillation protocol was used to purify the Os for analyses (Brick et al. 1997; Selby and Creaser 2001). The Re was processed separately by taking the remaining inverse aqua-regia solution through an anion chromatography procedure.

The Os isotopic compositions were determined by the N-TIMS method (Negative-Thermal Ionization Mass Spectrometry) on a ThermoFisher Triton TIMS. The Re isotopic compositions were analysed using the ID-ICP-MS method (Isotope Dilution Inductively Coupled Plasma Mass Spectrometry) on a ThermoFisher ELEMENT XR ICP-MS. The average blanks during this study were 3.4 picogram for Re, and 0.02 picogram for Os. For the present analyses, the measured Re and Os concentrations of homogenised asphaltene isolated from NIST Research Material 8505 (RM 8505) crude oil were 16.128-16.699 parts per billion (ppb, $10^{-9}$ ) and 162.31-166.88 parts per trillion (ppt, 10 $0^{-12}$ ), with ${ }^{187} \mathrm{Re} /{ }^{188} \mathrm{Os}$ and ${ }^{187} \mathrm{Os} /{ }^{188} \mathrm{Os}$ ratios of 571.6-573.2 and $1.612-1.640$, respectively (Table 1 ), consistent with previously published data by Liu and Selby (2018). The Re-Os mass fractions and isotopic compositions of asphaltene fractions from the terrestrial crude oils in the Hailar Basin are presented in Table 2.

\section{Results and discussion}

\subsection{Challenge of low Re-Os concentrations and mitigation procedures}

The asphaltene fractions of the Wuerxun-Beier Nantun oils contain $0.047-5.308 \mathrm{ppb} \mathrm{Re}$ and $1.07-13.97 \mathrm{ppt}$ Os (Table 2), values that are significantly lower than asphaltene fractions separated from crude oils in USA (Lillis and Selby 2013; Liu et al. 2019), UK (Finlay et al. 2011), Venezuela (Liu and Selby 2018), and the Persian Gulf (Liu et al. 2019), with tens to hundreds of ppb Re and several hundreds to thousands of ppt Os. Such low Re and Os concentrations may lead to higher analytical uncertainties, due to higher blank contributions (relative to the sample concentrations), as well as lower absolute precision of measured isotopic ratios for both Re and Os, induced by their low signal intensities at the limit of technique. To mitigate the influence of such challenges, we carried out thorough distillation of relevant chemicals (e.g. triple-distilled $\mathrm{H}_{2} \mathrm{O}_{2}$-purified concentrated nitric acid) and used new clean Teflon beakers in order to reduce blank levels, and created a specific spike for these low-level samples to minimise the weight error and optimize spike/sample ratio.

Table 1 Re-Os mass fractions and isotopic compositions of homogenised asphaltene from NIST Research Material 8505 (RM 8505 ) crude oil

\begin{tabular}{llllllrr}
\hline Sample & Re, ppb & $2 \sigma$ & Os, ppt & $2 \sigma$ & ${ }^{187} \mathrm{Re} /{ }^{188} \mathrm{Os}$ & $2 \sigma$ & ${ }^{187} \mathrm{Os} /{ }^{188} \mathrm{Os}$ \\
\hline RM NIST 8505-1 & 16.128 & 0.405 & 162.31 & 0.58 & 571.6 & 15.0 & 1.612 \\
RM NIST 8505-2 & 16.699 & 0.181 & 166.88 & 0.47 & 573.2 & 7.1 & 1.640 \\
\hline
\end{tabular}

ppb parts per billion, $10^{-9}$; ppt parts per trillion, $10^{-12}$ 
Table $2 \mathrm{Re}-\mathrm{Os}$ isotopic compositions of asphaltene fractions from the terrestrial crude oils in the Hailar Basin

\begin{tabular}{|c|c|c|c|c|c|c|c|c|c|c|c|c|}
\hline Sample & Well & Depth, m & Formation & $\mathrm{Re}, \mathrm{ppb}$ & $2 \sigma$ & Os, ppt & $2 \sigma$ & ${ }^{187} \mathrm{Re} /{ }^{188} \mathrm{Os}$ & $2 \sigma$ & ${ }^{187} \mathrm{Os} /{ }^{188} \mathrm{Os}$ & $2 \sigma$ & Rho \\
\hline 6 & $\mathrm{BaX} 2$ & 1835-1939.8 & Nantun & 0.451 & 0.007 & 3.33 & 0.03 & 720.6 & 19.6 & 0.922 & 0.028 & 0.617 \\
\hline 67 & Bei13 & $1583-1593$ & Nantun & 0.097 & 0.002 & 3.37 & 0.02 & 147.7 & 4.0 & 0.660 & 0.018 & 0.286 \\
\hline 26 & Bei17 & $1438-1453$ & Nantun & 5.308 & 0.103 & 3.97 & 0.12 & 6614.6 & 485.0 & 0.337 & 0.076 & 0.301 \\
\hline 25 & Bei20 & 1887-1919 & Nantun & 0.598 & 0.004 & 3.15 & 0.07 & 920.9 & 50.0 & 0.162 & 0.033 & 0.260 \\
\hline 27 & Bei23 & $1456.4-1493$ & Nantun & 0.280 & 0.004 & 13.97 & 0.31 & 100.7 & 5.4 & 0.465 & 0.036 & 0.660 \\
\hline 104 & Bei38 & 2299-2304 & Nantun & 0.107 & 0.002 & 2.54 & 0.02 & 211.4 & 6.1 & 0.415 & 0.013 & 0.370 \\
\hline $10 \mathrm{R}$ & Su12 & $1309-1356.8$ & Nantun & 0.083 & 0.010 & 2.45 & 0.07 & 172.6 & 23.4 & 0.594 & 0.053 & 0.377 \\
\hline 3 & Su132 & $1850-1856$ & Nantun & 0.275 & 0.004 & 1.94 & 0.03 & 868.9 & 24.9 & 2.242 & 0.077 & 0.618 \\
\hline 95 & Su132 & $1876.8-1878$ & Nantun & 2.497 & 0.052 & 12.68 & 0.09 & 1077.0 & 27.1 & 1.161 & 0.041 & 0.222 \\
\hline 88 & $\mathrm{Su} 21$ & $1188.8-1193$ & Nantun & 0.054 & 0.001 & 7.67 & 0.19 & 34.3 & 2.1 & 0.197 & 0.036 & 0.279 \\
\hline $77 \mathrm{R}$ & Su31 & $1744-1755$ & Nantun & 0.117 & 0.022 & 2.29 & 0.07 & 277.4 & 56.4 & 1.099 & 0.095 & 0.315 \\
\hline 52 & Su33 & $1719.4-1799.4$ & Nantun & 0.064 & 0.002 & 1.07 & 0.02 & 299.4 & 13.2 & 0.465 & 0.028 & 0.453 \\
\hline 90 & $\mathrm{Su} 48$ & $1848.4-1856$ & Nantun & 0.105 & 0.003 & 6.51 & 0.08 & 80.3 & 3.0 & 0.377 & 0.019 & 0.423 \\
\hline 16 & Wu29 & $2493-2572$ & Nantun & 0.259 & 0.002 & 3.38 & 0.12 & 387.1 & 33.7 & 0.487 & 0.061 & 0.691 \\
\hline 17 & Wu30 & $1671-1675$ & Nantun & 0.710 & 0.011 & 2.20 & 0.07 & 2846.7 & 124.4 & 6.469 & 0.321 & 0.763 \\
\hline 21 & Wu51 & $1471-1474$ & Nantun & 0.047 & 0.001 & 1.07 & 0.01 & 221.8 & 8.1 & 0.462 & 0.016 & 0.428 \\
\hline $42 \mathrm{R}$ & Wu55 & 1526.6-1529 & Nantun & 0.492 & 0.015 & 1.12 & 0.02 & 2126.3 & 125.9 & 0.197 & 0.029 & 0.287 \\
\hline 51 & Xi9 & $2620-2624$ & Nantun & 0.497 & 0.004 & 4.76 & 0.36 & 503.0 & 87.1 & 0.131 & 0.089 & 0.253 \\
\hline
\end{tabular}

$p p b$ parts per billion, $10^{-9}$; ppt parts per trillion, $10^{-12}$; Rho, associated error correlation at $2 \sigma$ (Ludwig 1980)

\subsection{Re-Os geochronology of the Hailar oils}

The samples have variable ${ }^{187} \mathrm{Re} /{ }^{188} \mathrm{Os}$ ratios ranging from 34.3 to 6614.6 , and exhibit ${ }^{187} \mathrm{Os} /{ }^{188} \mathrm{Os}$ ratios ranging from relatively non-radiogenic $(0.131)$ to radiogenic (6.469) (Table 2). Considering that the source wells range from 10 to $100 \mathrm{~km}$ apart, it is unlikely that the Wuerxun-Beier crude samples represent a single population despite them all being sourced from the $\mathrm{K}_{1} n$ Formation (Lu et al. 2012; Ping et al. 2013; Wang et al. 2018). The fact that no single linear trend is evident in the Re-Os results (Fig. 5) confirms the lack of a single population, with the regression of all Nantun oils yielding only a nominal Model 3 (indicating excess, "geologic" scatter) Re-Os age of $13 \pm 28 \mathrm{Ma}$ $(2 \sigma)$, with significant uncertainty $(215 \%)$ and a considerable mean square weighted deviation (MSWD) of 456.

Three separate trends, however, were observed in the results (Fig. 5), and each subgroup was regressed individually to test for possible age significance (Table 3 and Fig. 6). Population A trend consists of seven oils which yielded an Early Cretaceous age of $131.1 \pm 8.4 \mathrm{Ma}$, with an initial ${ }^{187} \mathrm{Os} /{ }^{188} \mathrm{Os}$ value of $0.29 \pm 0.12$ (Fig. 6b). Population B consists of six oils yielding a Tertiary age of $54 \pm 12 \mathrm{Ma}$, and an initial ${ }^{187} \mathrm{Os} /{ }^{188} \mathrm{Os}$ value of $0.22 \pm 0.11$ (Fig. 6c). Finally, Population C represents five relatively non-radiogenic oils yielding a Pleistocene age of $1.28 \pm 0.69 \mathrm{Ma}$ and an initial ${ }^{187} \mathrm{Os} /{ }^{188} \mathrm{Os}$ value of $0.16 \pm 0.02$ (Fig. $6 \mathrm{~d}$ ).

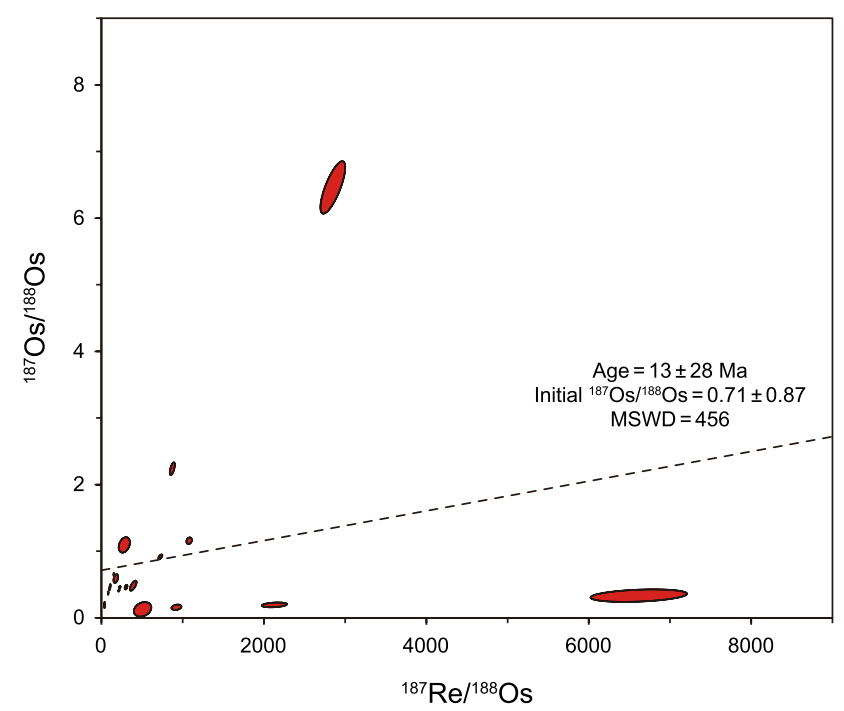

Fig. $5{ }^{187} \mathrm{Re} /{ }^{188}$ Os versus ${ }^{187} \mathrm{Os} /{ }^{188}$ Os plot showing all of the Re-Os data for the Wuerxun-Beier Nantun oils in the Hailar Basin. The nominal Model 3 (indicating excess, "geologic" scatter) Re-Os age was regressed using the ISOPLOT program (ver. 4.15) (Ludwig

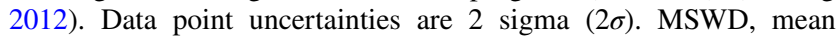
square weighted deviation

\subsection{Linking Re-Os ages to petroleum system evolution}

The Early Cretaceous Re-Os isochron age of $131.1 \pm 8.4 \mathrm{Ma}$ for the Wuerxun-Beier Nantun oils (Table 3 and Fig. 6b) is 
Table 3 Re-Os geochronology results of terrestrial crude oils in the Hailar Basin

\begin{tabular}{llllllllll}
\hline $\begin{array}{l}\text { Popu- } \\
\text { lation } \\
\text { No }\end{array}$ & $n$ & Age (Ma) & $2 \sigma$ & MSWD & Model & $\mathrm{Os}_{\mathrm{i}}$ & $2 \sigma$ & Samples & Description \\
\hline A & 7 & 131.1 & 8.4 & 26 & 3 & 0.29 & 0.12 & $3,10 \mathrm{R}, 17,27,67,77 \mathrm{R}, 90$ & Early Cretaceous hydrocarbon generation \\
B & 6 & 54 & 12 & 15 & 3 & 0.22 & 0.11 & $6,16,21,52,95,104$ & $\begin{array}{c}\text { Cenozoic multiple hydrocarbon generation or } \\
\text { expulsion }\end{array}$ \\
C & 5 & 1.28 & 0.69 & 2.4 & 1 & 0.161 & 0.024 & $25,26,42 \mathrm{R}, 51,88$ & $\begin{array}{c}\text { Cenozoic multiple hydrocarbon generation or } \\
\text { expulsion }\end{array}$ \\
\hline
\end{tabular}

$n$ number of samples, $M S W D$ mean square weighted deviation

Model number is from Ludwig (2012); Os , initial ${ }^{187} \mathrm{Os} /{ }^{188}$ Os value
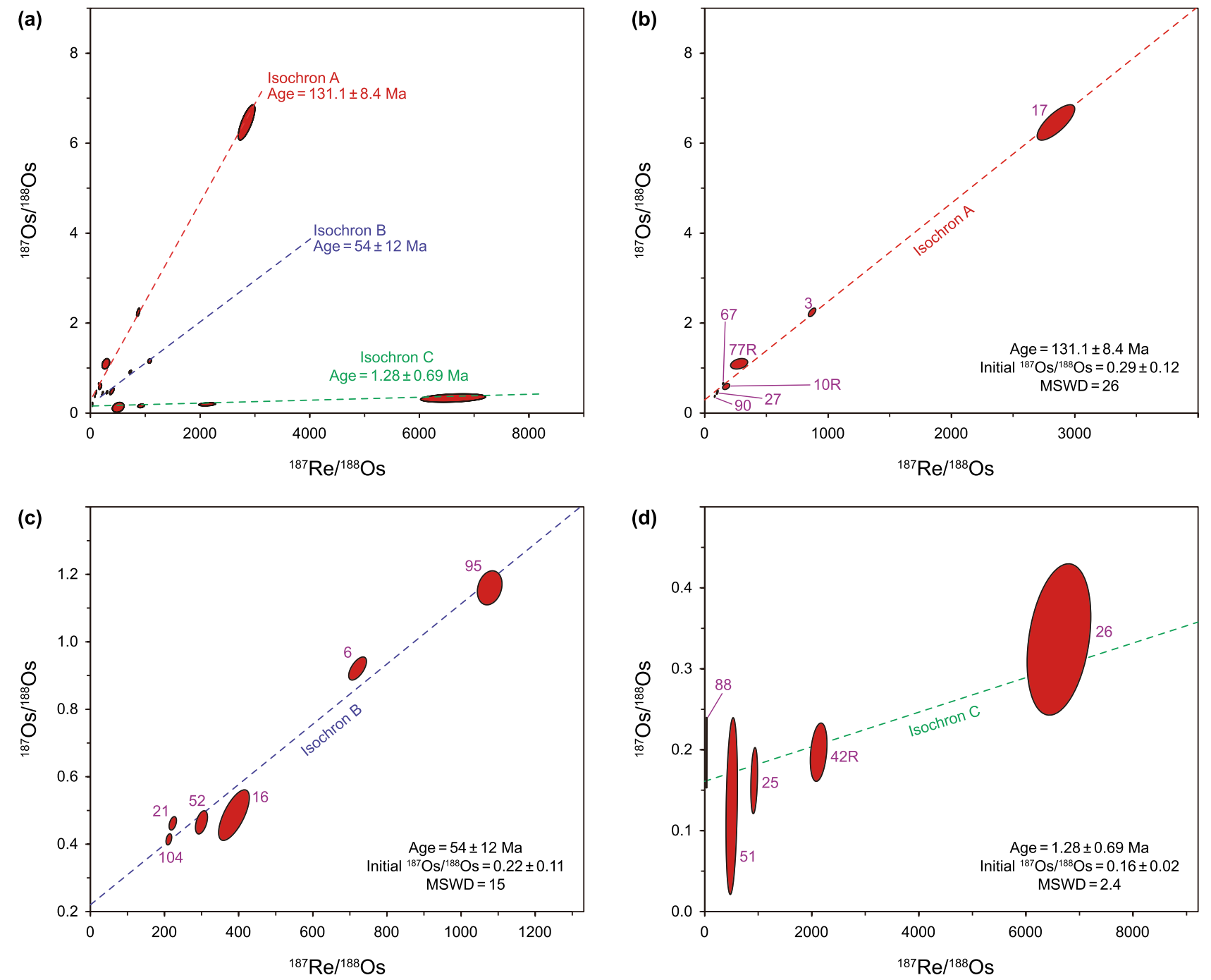

Fig. 6 Re-Os isochron diagrams for the Wuerxun-Beier Nantun oils in the Hailar Basin, showing the calculated regression ages. Regressions

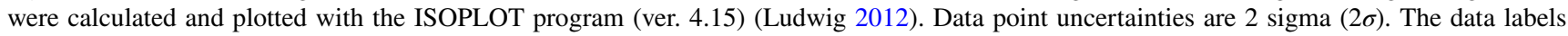
in italics indicate the oil sample numbers listed on Tables 2 and 3. MSWD, mean square weighted deviation. a Re-Os isotope data of all the Wuerxun-Beier Nantun oils. b Re-Os isochron for Population A. c Re-Os isochron for Population B. d Re-Os isochron for Population C 
equivalent to the chronostratigraphic age of the $\mathrm{K}_{1} n$ Formation (131-136 Ma; He et al. 2013), and suggests that these hydrocarbon samples may have been generated within 10 million years of deposition indicating a period of rapid sedimentation and burial. The Re-Os age is concordant with independently derived thermal models of hydrocarbon generation based on apatite fission-track dating (Cui and Ren 2011).

Regressions of the remaining oils yield two Cenozoic Re-Os isochron ages of $54 \pm 12$ Ma (Population B) and $1.28 \pm 0.69 \mathrm{Ma}$ (Population C) (Table 3 and Fig. 6c, d) implying that the Wuerxun-Beier Nantun oils do not represent a single population despite them all being sourced from the $\mathrm{K}_{1} n$ Formation (see Sect. 2). Apatite fission-track dating (Cui and Ren 2011) has demonstrated that multiple re-heating events have occurred since the Tertiary, which if correct, provides corroboration that the Cenozoic Re-Os ages can be interpreted as oil maturation-expulsion events linked to a later period of basin evolution. Structural geology and stress field analysis studies (Liu et al 2012) also provide evidence for Cenozoic disturbances of the Hailar Basin, yet it is unknown whether these events are significant enough to generate significant volumes of compartmentalised hydrocarbons.

As illustrated by this study in the Hailar Basin, Re-Os radiometric dating of lacustrine-sourced natural crude oils can be extremely challenging. This is due not only to higher analytical uncertainties for the low to ultra-low Re and Os concentrations in the asphaltene fractions of some oil samples (Table 2), but also be further hampered by multiple tectonic and hydrocarbon generation events in many basins (Cui and Ren 2011; Liu et al 2012). However, hydrocarbon $\mathrm{Re}-\mathrm{Os}$ geochronology can aid in quantitatively constraining the temporal evolution of petroleum system in a terrestrial petroliferous basin, especially when the results can be crosschecked and augmented by additional dating methods (e.g. apatite fission-track, fluid inclusions analysis, basin modelling, in situ $\mathrm{U}-\mathrm{Pb}$ dating of carbonates, and in situ $\mathrm{Rb}-\mathrm{Sr}$ and (U-Th)/He dating of siliciclastic sediments, etc.) and organic geochemistry (e.g. chemometric methods, biomarkers, clumped isotope, and site-specific stable isotope technologies, etc.).

\section{Conclusions}

This study presents new Re-Os geochronology for lacustrine crude oils from the Wuerxun-Beier depression of Hailar Basin in NE China. Corroborated with previous basin modelling and apatite fission-track analysis, the Re-Os dating of these oils is interpreted to provide an absolute age of $131.1 \pm 8.4 \mathrm{Ma}$ of an Early Cretaceous hydrocarbon generation event in the Wuerxun-Beier lacustrine petroleum system. Further work is necessary to validate the geological significance of the younger Re-Os isochron ages of $54 \pm 12 \mathrm{Ma}$ and $1.28 \pm 0.69 \mathrm{Ma}$. This case study represents the first successful application of the Re-Os geochronometer to quantitatively constrain the absolute timing of petroleum generation in a terrestrial basin.

Acknowledgements This research was funded by Daqing Oilfield Co., Ltd. project entitled "Geochronology and oil-source rock correlations in complex reservoirs (No. DQYT-1201002-2018-JS-150)", and PetroChina Co., Ltd. project (No. 2016E-0202). The authors would like to appreciate Dr. Chunhua Shi for his assistance with sampling.

Open Access This article is licensed under a Creative Commons Attribution 4.0 International License, which permits use, sharing, adaptation, distribution and reproduction in any medium or format, as long as you give appropriate credit to the original author(s) and the source, provide a link to the Creative Commons licence, and indicate if changes were made. The images or other third party material in this article are included in the article's Creative Commons licence, unless indicated otherwise in a credit line to the material. If material is not included in the article's Creative Commons licence and your intended use is not permitted by statutory regulation or exceeds the permitted use, you will need to obtain permission directly from the copyright holder. To view a copy of this licence, visit http://creativecommons.org/licenses/by/4.0/.

\section{References}

Baioumy HM, Eglinton LB, Peucker-Ehrenbrink B. Rhenium-osmium isotope and platinum group element systematics of marine versus non-marine organic-rich sediments and coals from Egypt. Chem Geol. 2011;285(1):70-81. https://doi.org/10.1016/j.chemg eo.2011.02.026.

Bertoni ME, Rooney AD, Selby D, et al. Neoproterozoic Re-Os systematics of organic-rich rocks in the São Francisco Basin, Brazil and implications for hydrocarbon exploration. Precambr Res. 2014;255:355-66. https://doi.org/10.1016/j.preca mres.2014.10.010.

Birck JL, Barman MR, Capmas F. Re-Os isotopic measurements at the femtomole level in natural samples. Geostand Geoanal Res. 1997;21(1):19-27. https://doi.org/10.1111/j.1751-908X.1997. tb00528.x.

Cohen AS. The rhenium-osmium isotope system: applications to geochronological and palaeoenvironmental problems. J Geol Soc. 2004;161(4):729-34. https://doi.org/10.1144/0016-764903-084.

Cohen AS, Coe AL, Bartlett JM, et al. Precise Re-Os ages of organicrich mudrocks and the Os isotope composition of Jurassic seawater. Earth Planet Sci Lett. 1999;167(3):159-73. https://doi. org/10.1016/S0012-821X(99)00026-6.

Creaser R, Szatmari P, Milani E. Extending Re-Os shale geochronology to lacustrine depositional systems: a case study from the major hydrocarbon source rocks of the Brazilian Mesozoic marginal basins. In: Proceedings of the 33rd international geological congress, Oslo; 2008.

Cui J, Ren Z. Thermal history of Wuerxun depression in Hailaer Basin, Inner Mongolia. Geoscience. 2011;25(4):668-74 (in Chinese).

ExxonMobil. Outlook for energy: a perspective to 2040. Irving, Texas: ExxonMobil. 2019; 1-54.

Finlay AJ, Selby D, Osborne MJ. Re-Os geochronology and fingerprinting of United Kingdom Atlantic margin oil: 
Temporal implications for regional petroleum systems. Geology. 2011;39(5):475-8. https://doi.org/10.1130/G31781.1.

Ge X, Shen C, Selby D, et al. Apatite fission-track and Re-Os geochronology of the Xuefeng uplift, China: Temporal implications for dry gas associated hydrocarbon systems. Geology. 2016;44(6):491-4. https://doi.org/10.1130/G37666.1.

Ge X, Shen C, Selby D, et al. Petroleum-generation timing and source in the northern Longmen Shan thrust belt, Southwest China: implications for multiple oil-generation episodes and sources. AAPG Bull. 2018;102(5):913-38. https://doi.org/10.1306/07111 71623017125.

Georgiev SV, Stein HJ, Hannah JL, et al. Comprehensive evolution of a petroleum system in absolute time: the example of Brynhild, Norwegian North Sea. Chem Geol. 2019;522:260-82. https://doi. org/10.1016/j.chemgeo.2019.05.025.

Gong YJ. Research on the reservoir-forming stages in southern Wuerxun depression of Hailaer Basin. Glob Geol. 2012;31(4):748-52 (in Chinese).

He L, Meng Q, Lu Y, et al. Analysis of sequence architecture for prediction of hydrocarbon reservoirs in early cretaceous deposits in the Wuerxun Sag in northeastern China. In: Proceedings of the CSPG/CSEG/CWLS GEOCONVENTION 2013, Calgary; 2013.

Li Z, Wang X, Liu K, et al. Rhenium-osmium geochronology in dating petroleum systems: progress and challenges. Shiyou Xuebao/Acta Petrolei Sinica. 2017;38:297-306 (in Chinese).

Lillis PG, Selby D. Evaluation of the rhenium-osmium geochronometer in the Phosphoria petroleum system, Bighorn Basin of Wyoming and Montana, USA. Geochim Cosmochim Acta. 2013;118:312 30. https://doi.org/10.1016/j.gca.2013.04.021.

Liu J, Selby D. A matrix-matched reference material for validating petroleum Re-Os measurements. Geostand Geoanal Res. 2018;42(1):97-113. https://doi.org/10.1111/ggr.12193.

Liu H, Hou Y, Jiang L, et al. Oil-gas enrichment in the central fault zone of Hailar-Tamtsag Basin. Heilongjiang, China: Daqing Oilfield Co. Ltd.; 2012. p. 1-197 (in Chinese).

Liu J, Selby D, Zhou H, et al. Further evaluation of the Re-Os systematics of crude oil: implications for Re-Os geochronology of petroleum systems. Chem Geol. 2019;513:1-22. https://doi. org/10.1016/j.chemgeo.2019.03.004.

Lu S, Chen F, Li J, et al. Identification of the lower limit of high-quality source rocks and its relation to hydrocarbon accumulation-taking the Beier Sag in the Hailaer Basin as an example. Pet Sci. 2012;9(1):10-7. https://doi.org/10.1007/s12182-012-0176-y.

Ludwig KR. Calculation of uncertainties of $\mathrm{U}-\mathrm{Pb}$ isotope data. Earth Planet Sci Lett. 1980;46(2):212-20. https://doi.org/10.1016/0012821X(80)90007-2.

Ludwig KR. Isoplot version 4.15: a geochronological toolkit for Microsoft Excel. Berkeley Geochronology Center, Special publication. 2012. (5): 1-75.
Ping GD, Lü YF, Fan LM, et al. Rules and main controlling factors of hydrocarbon enrichment of Urxun-Beier depression, Hailaer Basin. J Cent South Univ (Sci Technol). 2013;44(10):4167-78 (in Chinese).

Ravizza G, Turekian KK. Application of the ${ }^{187} \mathrm{Re}-{ }^{187} \mathrm{Os}$ system to black shale geochronometry. Geochim Cosmochim Acta. 1989;53(12):3257-62. https://doi.org/10.1016/00167037(89)90105-1.

Rooney AD, Selby D, Houzay J-P, et al. Re-Os geochronology of a Mesoproterozoic sedimentary succession, Taoudeni basin, Mauritania: implications for basin-wide correlations and Re-Os organicrich sediments systematics. Earth Planet Sci Lett. 2010;289(34):486-96. https://doi.org/10.1016/j.epsl.2009.11.039.

Selby D, Creaser RA. Re-Os geochronology and systematics in molybdenite from the Endako porphyry molybdenum deposit, British Columbia, Canada. Econ Geol. 2001;96(1):197-204. https://doi. org/10.2113/gsecongeo.96.1.197.

Selby D, Creaser RA. Direct radiometric dating of hydrocarbon deposits using rhenium-osmium isotopes. Science. 2005a;308(5726):1293-5. https://doi.org/10.1126/science.11110 8.

Selby D, Creaser RA. Direct radiometric dating of the DevonianMississippian time-scale boundary using the Re-Os black shale geochronometer. Geology. 2005b;33(7):545-8. https://doi. org/10.1130/G21324.1.

Selby D, Creaser RA, Fowler MG. Re-Os elemental and isotopic systematics in crude oils. Geochim Cosmochim Acta. 2007;71(2):378-86. https://doi.org/10.1016/j.gca.2006.09.005.

Stein H, Hannah J. Rhenium-osmium geochronology: Sulfides, shales, oils, and mantle. In: Rink JW, Thompson JW, editors. Encyclopedia of scientific dating methods. Dordrecht: Springer; 2015. p. 707-23.

Wang Y-P, Zhang F, Zou Y-R, et al. Oil source and charge in the Wuerxun depression, Hailar Basin, northeast China: a chemometric study. Mar Pet Geol. 2018;89:665-86. https://doi. org/10.1016/j.marpetgeo.2017.10.032.

Wu HY, Li ZS, Feng ZH, et al. Analysis on structural features and reservoir-forming process of Wuerxun and Beier sags in Hailaer Basin. Acta Pet Sinica. 2006;27(SUPPL):1-6 (in Chinese).

Zhang JG, Peng SP. The oil/gas reservoir types in Wuerxun-Beier faulted-down depression and their exploration methods. Pet Explor Dev. 2002;29(3):48-50 (in Chinese).

Zhu B, Becker H, Jiang S-Y, et al. Re-Os geochronology of black shales from the Neoproterozoic Doushantuo Formation, Yangtze platform, South China. Precambr Res. 2013;225:67-766. https:// doi.org/10.1016/j.precamres.2012.02.002. 